\title{
Characterizing Diversity Based on Phenotypes and Molecular Marker Analyses of Purple Yam (Dioscorea Alata) Germplasm in Southern China
}

\section{Xin Chen}

Jiangxi Agricultural University

Jingyu Sun

Jiangxi Agricultural University

Qianglong Zhu

Jiangxi Agricultural University

Yao Xiao

Jiangxi Agricultural University

Hongyu Zhang

Jiangxi Agricultural University

Yingjin Huang

Jiangxi Agricultural University

Putao Wang

Jiangxi Agricultural University

Tianxu Cao

Yangtze Normal University

Rui Hu

Jiangxi Agricultural University

Zijin Xiang

Jiangxi Agricultural University

Nan Shan

Jiangxi Agricultural University

Qinghong ZHOU ( $\sim$ qinghongzhou@126.com )

Jiangxi Agricultural University https://orcid.org/0000-0002-8552-7738

\section{Research Article}

Keywords: Purple yam, Morphological traits, SSR markers, Genetic diversity analysis, Population structure

Posted Date: November 8th, 2021

DOl: https://doi.org/10.21203/rs.3.rs-981362/v1 
License: (c) (i) This work is licensed under a Creative Commons Attribution 4.0 International License. Read Full License 


\section{Abstract}

Purple yam (Dioscorea alata L.), which is widely distributed in southern China, is characterized by great purple to red flesh or skin, as well as nutritional and medical values. However, their intraspecific genetic diversity remains unknown, which inhibits the germplasm innovation and variety protection of purple yams. In this study, genetic diversity of 26 landraces from southern China were carried out by using 17 morphological traits and 9 simple sequence repeat (SSR) markers, respectively. Results of phenotypic traits showed that all the accessions were divided into four groups at the euclidean distance of 1.43, and there is high correlation between the taxa and the regional distribution of yam accessions. The group IV includes the most accessions mainly from Jiangxi province, followed by group III, which contained accessions mostly from Fujian province. In addition, the leaf shape, leaf vein color and tuber flesh color, displayed higher Shannon's diversity index ( () and variation coefficient, which could identify the purple yam resources effectively. Based on the SSR markers analysis, the euclidean distance among all germplasms ranged from 0.17 to 0.79 , and the 26 landraces were also clearly separated into four clusters at the euclidean distance of 0.49 . Clustering results based on SSR markers and phenotypic traits were consistent roughly. Furthermore, population structure revealed the existence of three sub-populations in all accessions. These results demonstrate the genetic diversity and distinctness among the purple yam from southern China and provide a theoretical basis for the identification and utilization of purple yams.

\section{Introduction}

Yam, the plant species of the genus Dioscorea, is grown for their edible and medical tubers. Purple yam is typically characterized by purple to red flesh or skin, which is rich in functional components, such as polyphenols, diosgenin, allantoin (Bhandari and Kawabata, 2004; Chiang et al., 2010; Shah and Lele, 2012). Specially, purple yam contains a variety of acylated anthocyanins with high antioxidant activity (Moriya et al., 2015; Srivichai and Hongsprabhas, 2020). In recent years, the purple yam has attracted much attention from various industries.

Purple yam is widely distributed and cultivated in southern China (Moriya et al., 2015). Their aboveground parts are highly similar, with lavender-red edge on wings of stem, and purplish red ends on their petioles. However, extensive diversities of underground parts are preserved, including varieties in tuber shape, skin characteristics, and flesh color (Sheela et al., 2016). Due to its uniqueness, purple flesh yam is one of the most popular varieties of Chinese yam, and is also favored by researchers and famers who are interested in selective breeding (Wenqiang et al., 2019).

Purple yambelongs to the species of Dioscorea alata L., and D. alata is one of the most polymorphic species in the genus Dioscorea (Siqueira et al., 2011). For example, morphological and molecular analysis showed that there were genotypic divergences among $D$. alata accessions from southern and northeastern states of India (Sheela et al., 2016). By assessing the genetic diversity of nine yam species from India, it was found that high genetic heritability of the major morphological traits were major determinants of phenotypic diversity (Padhan et al., 2019). Agre et al. (2019) evaluated the genetic 
diversity of 100 winged-yam (D. alata) resources by combining phenotypic traits and molecular markers, and clustered these accessions into three groups. The genetic diversity of 142 Chinese greater yams was evaluated by analyzing their morphology, genotype, chromosome and ploidy, and showed that they could be divided into two groups (Wenqiang et al., 2019). These results indicated that the genetic diversity for $D$. alata could provide a basis for the identification of heterotic populations in breeding.

However, because purple yam is not considered a staple food crop and is mostly landrace, the research on the genetic diversity of purple yam is limited. Farmers usually distinguish varieties by long experience, which is very ambiguous. To analyze the genetic diversity of purple yams in southern China, we clarified the genetic diversity of purple yams by morphological and simple sequence repeat (SSR) markers analysis, which will provide scientific basis for the protection and rational utilization of purple yams in southern China.

\section{Materials And Methods}

\section{Plant material and crop management}

A total of 26 accessions of purple yams were collected from southern China (Table S1). All collections were planted in yam germplasm resource garden of Jiangxi Agricultural University (115.84E, 28.77N, Nanchang City, Jiangxi province). Three replicates were performed for each accession, and 10 individual plants were planted in each replicate. There were $20 \mathrm{~cm}$ distance for each individual plant and $1.2 \mathrm{~m}$ distance between ridges. Tuber segments $(80 \sim 100 \mathrm{~g})$ were used as seeds. Standard field management measures were used to provide appropriate plant growth conditions.

\section{Morphological characterization}

Morphological observation and measurements were conducted by using 17 phenotypic traits (Table 1), including 12 qualitative traits (leaf shape, leaf color, petiole color, leaf margin color, leaf vein color, leaf texture, stem wing color, the root number of the tuber surface, position of roots on the tuber, tuber flesh texture, tuber skin color, and tuber flesh color) and five quantitative traits (leaf length, leaf width, petiole length, concave depth of leaf base, and distance between lobes). Three plants of each accession and 10 leaves from each plant were randomly selected for evaluating above traits, and the descriptors and data standard for purple yams were referred in Wang and Shen (2014).

\section{DNA extraction and SSR genotyping}

Yam young leaves of each accession were collected for DNA extraction. DNA was extracted using a TaKaRa MiniBEST plant genomic DNA Extraction Kit (Beijing, China) according to the manufacturer's instructions. DNA samples were quantified with a NanoDrop 2000 spectrophotometer (Wilmington, USA) 
and visualized on a $1.0 \%$ agarose gel stained with ethidium bromide. All DNA samples were stored at $-20^{\circ} \mathrm{C}$ for further analysis.

Nine SSR primer pairs with polymorphic bands were screened out from the original 21 SSR markers for amplicon in all accessions (Muluneh et al., 2015; Table 4; Table S5). Amplification reaction system were conducted in a $20 \mu \mathrm{L}$ volume, including $10 \mu \mathrm{L}$ of $2 \times$ Master Mix Blue (TSINGKE, China), $0.5 \mu \mathrm{L}$ of each primer $(10 \mathrm{mM})$, and $1.5 \mu \mathrm{L}$ of template DNA $(20 \mathrm{ng} / \mu \mathrm{L})$, and the remaining volume was supplemented with $\mathrm{dd}_{2} \mathrm{O}$. Amplification procedure was performed as follow: predegeneration at $94^{\circ} \mathrm{C}$ for $5 \mathrm{~min}$; denaturation at $94^{\circ} \mathrm{C}$ for $30 \mathrm{~s}$, annealing at $54^{\circ} \mathrm{C}$ for 30 s, extension at $72^{\circ} \mathrm{C}$ for $30 \mathrm{~s}$, and in total 40 cycles; extended at $72^{\circ} \mathrm{C}$ for $10 \mathrm{~min}$ and stored at $4^{\circ} \mathrm{C}$. Amplified products were separated in $8 \%$ polyacrylamide gels electrophoresis at $60 \mathrm{~V}$ for $30 \mathrm{~min}$ and $220 \mathrm{~V}$ for $3 \mathrm{~h}$. The products were visualized by silver staining according to Creste et al. (2001).

\section{Statistical analysis}

SPSS 22.0 was used to calculate the standard deviation (SD) and variation coefficient (CV). Quantitative traits were classified based on Du et al. (2019) and Liang et al. (2016). Shannon's diversity index (I) was used to calculate the diversity index of each trait by formula:

$$
I=\sum_{i=1}^{n}(p i)(\ln p i)
$$

where pi represents the relative frequency of the ith phenotypic class of a trait (Kouam et al., 2018).

Amplification bands of each primer for SSR markers in the range of $100 \sim 400$ bp were denoted as present (1) and absent (0), so as to obtain the band number and polymorphism percentage (polymorphic band number/ total band number) of each pair of primers. The observed number of alleles $\left(N_{\mathrm{a}}\right)$, effective number of alleles $\left(N_{\mathrm{e}}\right)$, Shannon's diversity index $(I)$, and Nei's gene diversity index $(H)$ of each SSR primer pair were calculated with POPGENE software version 1.32 (Yeh Francis et al., 1999). Two-dimensional dendrograms were constructed based on Euclidean distance and genetic similarity coefficient matrix using the unweighted pair-group method with arithmetic average (UPGMA) with the SAHN module of NTSYS-pc 2.10 (Rohlf, 2000). The SSR data were further analyzed via a Bayesian model in STRUCTURE software version 2.3.1 to detect population genetic structure (Pritchard et al., 2000). STRUCTURE HARVESTER (Earl and vonHoldt, 2011), which determines the best $K$ based on the probability of data given $\mathrm{K}$ and $\Delta \mathrm{K}$ (Evanno et al., 2005), was used to estimate the most likely number of clusters (K).

\section{Results}

\section{Morphological characterization analysis}


A wide range of morphological variations for purple yams were shown in this study (Fig.1; Table 1; Table 3). There were ten qualitative and five quantitative traits showed great variability across all accessions with Shannon's diversity index (/) ranging from 0.391 to 2.120 (Table 2; Table 3). Specially, the traits of tuber flesh color, leaf vein color, and tuber skin color (/values is higher than 1.00) displayed greatest diversity in all qualitative traits (Table 2). The diversity of tuber flesh colors in 26 accessions showed that purple-red and purple tubers were mostly observed in accessions from Jiangxi Province, and the white-purple and outer purple-red tubers were mostly found in the Fujian Province, while outer-layer purple was only detected in tubers sampled from Sichuan Province (Table 2; Fig. 3). For skin color of tubers, brown was the main color of accessions from Jiangxi, Fujian and Sichuan provinces (Table 2; Fig. 3; Table S4). The veins of leaves were mostly purple and yellowish green, and a few are green (Table 2; Fig. 3). Two leaves shapes, namely 'sagittate' and 'ovate', were equally divided in all accessions. For leaves colors in all accessions, $46.2 \%$ leaves (12 out of 26 ) were dark green and $52.8 \%$ leaves (14 out of 26) were yellowish green. Similar results could be obtained from the distribution frequency (\%) of each trait in the four groups (Fig. 3; Table S4).

For all accessions, the CVs of the five quantitative traits ranged from $19.73 \%$ to $29.82 \%$, with the highest values for concave depth of leaf base and the lowest values for leaf length (Table 3 ). The ratio of maximum to minimum concave depth of leaf base was the largest (7.25), followed by distance between lobes (5.64), leaf width (4.10), petiole length (4.06), and leaf length (3.59; Table 3). Diversity index and variation coefficient reflected almost the same result.

The Euclidean distance among all individuals ranged from 0.42 to 2.60 (Table S2). All accessions were divided into four clusters evidently when Euclidean distance is 1.43 (Fig. 2A); only one accession (16) was classified as Group I (Fig. 2A; Table S4). Group II also only included an accession (23) with purple skin and white flesh from Fujian province;eight accessions (8, 13, 17-21 and 26) from Jiangxi, Sichuan and Fujian provinces respectively were clustered into Group III, and most of them mainly from Fujian province; Group IV included 16 accessions (1-7, 9-12, 14, 15, 22, 24 and 25), and most of them mainly from Jiangxi province. The result of the two-dimensional diagram showed the same tendency (Fig. 2B). Meanwhile, Only leaf margin color of Group III and roots and leaf texture of Group IV showed diversity (Table 2). Between the group III and group IV, the CVs of leaf length, leaf width, petiole length, concave depth of leaf base and distance between lobes in Group IV were higher than those in group III, and only the CV of concave depth of leaf base in Group IV were lower than those in group III.

\section{Polymorphism analysis of SSR marker}

A total of 49 bands and 48 polymorphic bands were amplified by nine pairs of primers (Table S5), and the percentage of polymorphic loci was $97.96 \%$. 32 pairs of alleles were amplified, and the largest $N_{a}$ values (five) were found using primers YM20, with an average of four alleles per primer (Table 4). The $\mathrm{Ne}$ values ranged from 1.374 to 3.655 with an average of 2.258 , the $\mathrm{H}$ values ranged from 0.272 to 0.726 with an average of 0.518 , and the / values were ranged from 0.536 to 1.409 , with a mean 
of 0.935 , it also suggested that YM20 can be used to distinguish most accessions (Table 4). Bsed on the SSR analysis, euclidean distance among all accessions ranged from 0.17 to 0.79 (Fig. 4A; Table S3). The euclidean distances was the lowest between Anyuan $L$ No.2, Zhouning $L$ and Yudu L No.2, Ruijin $L$ and Shanggao, while the euclidean distance was up to between Yudu $L$ No.6 and Miyi purple flower yam. Furthermore, three accessions from Sichuan province ("Panzhihua Powder Yam", "Miyi Purple Flower Yam", and "Miyi No.1",) possessed higher euclidean distances than other accessions. By UPGMA clustering, 26 accessions were divided into four groups at the euclidean distance of 0.49 (Fig. 4A). In group I, three accessions $(13,16$ and 26$)$ from Sichuan province were clustered, and group II included one accession (9) from Jiangxi province. Group III included seven accessions $(2,7,8,17,18,20$, and 22) from Jiangxi and Fujian province, and group IV contained 15 accessions mainly from Jiangxi province (Fig. 4A). The two-dimensional diagram showed the same result showed the same tendency (Fig. 4B). Compared with morphological clustering results (Fig. 2B), molecular cluster showed a more clear separation (Fig. 4B).

\section{Population structure analysis}

According to the output from STRUCTURE HARVESTER, when $\triangle \mathrm{K}$ was at a maximum, the optimal $\mathrm{K}$ value was 3 (Fig. 5A). At $K=2$, the 26 accessions were divided into two clusters, with red representing first cluster (12 accessions) and blue representing the second cluster (14 accessions). The first cluster was a collection of all group I, group II, group III accessions and part of accessions of group IV, and the second cluster was a collection of other accessions of group IV accessions. When $\mathrm{K}=3$, the 26 accessions were divided into three clusters, with group III except for one accession (13) and group IV clustered into separate subgroups, and the other accessions were clustered into another group. At $K=4$, the accessions were clustered into four subgroups (Fig. 5B).

\section{Discussion}

As a vegetative propagation tuber crop with few flowers and dioecism, yam has relatively few opportunities for genetic recombination (Wenqiang et al., 2019). Therefore, it is desirable to differentiate according to the diversity of geographical regions as it reflects a condition of distance isolation (Ngo Ngwe et al., 2015). Many researches on the morphological and molecular diversity of yams have been reported in recent years (Anokye et al., 2014; Wenqiang et al., 2019; Tianxu et al., 2021), which showed their rich genetic diversity among local varieties of D. alata in China. In this study, based on the cluster analysis by phenotypic traits, the purple yam resources were divided into four clusters (Fig. 2). Most of the accessions from the same area were grouped into one cluster, with relatively close Euclidean distance. The clustering results of phenotypic traits could accurately reveal the morphological differences among different accessions to some extent. $D$. alata is one of the most widely cultivated yam species globally. A wide range of morphological traits, such as flesh color, tuber shape and other morphology, can be found among $D$. alata accessions in the field of gene bank (Sheela et al., 2016). Although lots of varieties with different phenotypic characters was developed by Chinese farmers through long-term 
domestication process (Chen et al., 2016; Yin et al., 2017), it is difficult for them to distinguish Dioscorea family based on tuber shape diversity. Compared with other yam varieties, $D$. alata have unique phenotypic feature of wings in its stem (Wenqiang et al., 2019). In our study, the wings in stems of all purple yams were observed to be purple-red and the petiole bases were observed to be purple, which may be the characteristics of purple yam.

Molecular marker clustering showed that the germplasms could be divided into four clusters as well (Fig. 4). Most of the accessions from one region were clustered into one class and the genetic similarity coefficient was higher between them. However, some accessions from different geographic distribution are usually separated into the same clusters. In fact, breeding programs of Chinese yam mainly focused on direct selection within species (Wu et al., 2014). Thus, except the possibility of some similar environments, it was in all probability the frequent exchange of germplasms between farmers in the neighboring areas (Mwirigi et al., 2009; Siqueira et al., 2014). It is worth noting that there was a close euclidean distance between Yuan L No.2 and Yudu L No.2, Ruijin L and Shanggao L, Yudu L No.2 and Zhouning L (Fig. 4; Table S3), which may be resulted from the frequent exchange of germplasms between farmers in the neighboring areas, and may cause confusion across various records and nomenclatures. However, the euclidean distance between the accessions from Sichuan Province and those from other regions was far, which may be caused by the difference of geographical environment. The evaluation and utilization of genetic diversity is able to provide essential information for the exploration of genetic resources (Li et al., 2003; Wang et al., 2011a; Wang et al., 2011b). In this study, the average of polymorphism was over $97 \%$, indicated a high level of genetic diversity among purple yam varieties in southern China. The extent of the purple yams diversity detected in our study is comparable to a previous report involving $D$. alata (Wu et al., 2014). The diverse landraces of purple yam maintained by traditional farmers may be related to environmental suitability and the length of growing cycle. This finding further underscores the significance of farmers to preserve genetic diversity among the germplasms.

Due to the lack of the genomic DNA sequence information for yam, researchers used AFLP (Xu et al., 2014), RAPD (Zannou et al., 2009), ISSR (Rao et al., 2020) and SRAP (Wu et al., 2014) to estimate the genetic relationships of interspecific and intraspecific yams. However, more convenient, transportable, widespread, co-dominant and polymorphic markers, such as SSR, need to be developed to identify candidate genes and germplasm with high genetic diversity (Narina et al., 2012). Nine SSR makers selected in this study might be used as DNA fingerprints for identifying the landraces of purple yam in southern China (Table 4). The cluster analysis of 26 accessions based on the polymorphic data of SSR markers was similar to the cluster of phenotypic traits (Fig. 4). Compared with phenotypic clustering, all the accessions from Sichuan were clustered into one group (Group I) based on the polymorphic data of SSR markers. Although "Yudu L No.6" from Yudu County of Jiangxi Province was similar to other accessions from the county in phenotypic traits, it was divided into a separate group (Group II) for molecular markers. However, "Minghuai No.1" was different from other accessions in some phenotypic traits, and phenotypic clustering puts it into one group (Group II). However, it was not isolated into a group based on SSR markers data. Morphological clustering and molecular markers clustering also showed that some accessions from different geographic distribution were separated into the same clusters, which 
may be resulted from the frequent exchange of germplasms between farmers in the neighboring areas, and may cause confusion across various records and nomenclatures. Compared with phenotypic clustering, the molecular clustering could reflect the different genotypes among different accessions more accurately. Previous studies indicated D.alata had high genetic diversity in China with genetic similarity coefficients ranged from 0.42 to 0.91 (Wenqiang et al., 2019). Our data revealed that the purple yam landraces had a higher genetic diversity in southern China with genetic similarity coefficients ranged from 0.38 to 0.97 (Table S6). In addition, our observation about similarity in purple yams' morphological character from different geographic locations may provide some insights into the potential relationship between genes of purple yam varieties and environmental conditions.

Purple yam has typical features of stem wings, a long growth period, and strong growth potential (Agre et al., 2019; Wenqiang et al., 2019). Reproductive system, one of the important life-history characteristics, strongly influences genetic variability of plant. Purple yam is a vegetatively propagated species and the mating system of the species limits gene flow, which may be the reason why there was little gene exchange between subgroups of the population structure base on the optimal $\mathrm{K}$ value.

\section{Conclusions}

Purple yam has high nutritional and economic value, but there were few studies on its germplasm resources. In this study, considerable variations were found among 26 yam landraces in terms of morphological characterization and polymorphism of SSR markers. Seventeen phenotypic traits and nine SSR primer pairs with polymorphic bands were applied for characterizing the diversity respectively. Results of phenotypic traits and SSR markers both showed that all the accessions were divided into four groups, and the taxa and the regional distribution of yam accessions displayed high correlation. The distribution of these samples could be clearly separated and showed distinct differences. Further population structure revealed the existence of three sub-populations in the all accessions. Overall, the combination of morphological characterization and polymorphism of SSR marker provides a feasible classification of usage in purple yams. The classification is of great benefit in determining appropriate application strategies for purple yam germplasm in China.

\section{Declarations}

Acknowledgements This work was supported by the earmarked fund for Jiangxi Agriculture Research System (JXARS-19) and Jiangxi Provincial Key Research and Development Project (20192BBF60005, 20201BBF61002).

Authors' contributions QZ and NS: developing the concept, getting financial support, designing the lab experiments. XC: conducting lab experiments and writing paper. JS, QZ, YX and HZ: involved in sample collection. TC, RH and ZX performed experiments and statistical data analysis. JH and PW: modify paper. 
Funding Jiangxi Agriculture Research System (JXARS-19) and Jiangxi Provincial Key Research and Development Project (20192BBF60005, 20201BBF61002).

Conflict of interest The authors declare that they have no conflict of interest.

Ethics approval and consent to participate All authors agreed to participate in the study.

\section{Consent to Publish All authors agreed to publish this pape.}

\section{References}

Agre P, Asibe F, Darkwa K, Edemodu A, Bauchet G, Asiedu R, Adebola P, Asfaw A (2019) Phenotypic and molecular assessment of genetic structure and diversity in a panel of winged yam (Dioscorea alata) clones and cultivars. Sci Rep 9(1): 18221.

Anokye M, Tetteh JP, Otoo E (2014) Morphological characterization of some water yam (Dioscorea alata L.) germplasm in Ghana. J Agr Sci Tech-Iran 4: 518-532.

Bhandari MR, Kawabata J (2004) Organic acid, phenolic content and antioxidant activity of wild yam (Dioscorea spp.) tubers of Nepal. Food Chem 88(2): 163-168.

Chen ZH, Hua SM, Li LH, Lei FG, He PZ, Cao YY, Mo ZL, (2016) Breeding and application of a new yam cultivar "Minghuai No.1". Hunan Agr Sci 07: 18-20, 23.

Chiang SN, Wency C, Hung TW, Kai CC, Ya JW, Kao CL, Juei TC (2010) Decrease of plasma glucose by allantoin, an active principle of yam (Dioscorea spp.), in streptozotocin-induced diabetic rats. J Agric Food Chem 58(22): 12031-12035.

Du ZZ, Li X X, Song J P, Wu Y H, Zhao Q, Xu T, Zhang X H, Barbara H, Hu JG, Wang HP (2019) Phenotypic diversity and adaptability analysis of 228 accessions of introduced garlic genetic resources. J Plant Genet Resour 20: 1186-1196.

Earl DA, VonHoldt BM (2011) STRUCTURE HARVESTER: a website and program for visualizing STRUCTURE output and implementing the Evanno method. Conserv Genet Resour 4(2): 359-361.

Evanno G, Regnaut S, Goudet J (2005) Detecting the number of clusters of individuals using the software STRUCTURE: a simulation study. Mol Ecol 14(8): 2611-20.

Kouam E, Avana-Tientcheu M, Lekeumo V, Akitio H, Khasa D, Pasquet R (2018) Agro-ecological distribution of the phenotypic diversity of aerial yam (Dioscorea bulbifera L.) in Cameroon using multivariate analysis: Prospect for germplasm conservation and improvement. Open Agric 3(1): 190206. 
Li Z, Zhang A (2003) Progress of crop genetics and breeding in China. In: Lu Y X, ed. Science Progress in China (in Chinese). Beijing: Science Progress in China 237-253.

Liang J Y, Feng C Q, Song P (2016) A survey on correlation analysis of big data. Chin J Comput (1): 1-18.

Narina SS, Montegue P, Asiedu R, Mohamed Al (2012) Development of microsatellite markers for anthracnose resistance in greater yam (Dioscorea alata L.) from expressed sequence tags of heterologous crop species. J Root Crops 38(1): 64-69.

Ngo Ngwe MF, Omokolo DN, Joly S (2015) Evolution and Phylogenetic Diversity of Yam Species (Dioscorea spp.): Implication for Conservation and Agricultural Practices. PLoS One 10(12): e0145364.

Muluneh T, Shinsuke Y, Chikako M, Pachakkil B, Hiroko T, Antonio LM, Alieu S, Robert A, Ryohei T (2015) Development of genomic simple sequence repeat markers for yam. Crop Sci 55(5): 2191-2200.

Mwirigi P, Kahangi E, Nyende A, Mamati E (2009) Morphological variability within the Kenyan yam (Dioscorea spp.). J Appl Biosci 16: 894-901.

Padhan B, Mukherjee AK, Mohanty SK, Lenka SK, Panda D (2019) Genetic variability and inter species relationship between wild and cultivated yams (Dioscorea spp.) from Koraput, India based on molecular and morphological markers. Physiol Mol Biol Pla 25(5): 1225-1233.

Pritchard JK, Stephens M, Donnelly P (2000) Inference of population structure using multilocus genotype data. Genetics, 155(2):945-959.

Rao GK, Kapadia C, Patel NB, Desai KD, Narasimha Murthy PN (2020) Genetic diversity analysis of greater yam (Dioscorea alata L.) genotypes through RAPD and ISSR markers. Biocatal and Agr Biotechnol 23:101495.

Rohlf FJ (2000) NTSYS-Pc: Numerical taxonomy and multivariate analysis system. Version 2.1., Exeter Publishing Led., New York.

Shah HJ, Lele SS (2012) In vitro propagation of Dioscorea alata var. purpurae. Appl Biochem Biotechnol 167(6): 1811-1817.

Sheela MN, Abhilash PV, Asha KI, Arnau G (2016) Genetic diversity analysis in greater yam (Dioscorea alata L.) native to India using morphological and molecular markers. Acta Hortic 1118(1118): 51-58.

Siqueira MV, Marconi TG, Bonatelli ML, Zucchi MI, Veasey EA (2011) New microsatellite loci for water yam (Dioscorea alata, Dioscoreaceae) and cross-amplification for other Dioscorea species. Am J Bot 98(6): e144-6.

Siqueira MV, Bonatelli ML, Günther T, Gawenda I, Schmid KJ, Pavinato VA, Veasey EA (2014) Water yam (Dioscorea alata L.) diversity pattern in Brazil: an analysis with SSR and morphological markers. Genet 
Resour Crop Ev 61(3): 611-624.

Srivichai S, Hongsprabhas P (2020) Profiling anthocyanins in Thai purple yams (Dioscorea alata L.). Int J Food Sci 2020: 1594291.

Tianxu C, Jingyu S, Nan S, Xin C, Putao W, Qianglong Z, Yao X, Hongyu Z, Yingjin H (2021) Uncovering the genetic diversity of yams (Dioscorea spp.) in China by combining phenotypic trait and molecular marker analyses. Ecol Evol 00:1-17.

Wang SM, Li LH, Lu XX, Yang QW, Cao YS, Zhang ZW, Mo JM (2011a) Status of plant genetic resources for food and agricultural in China. J Plant Genet Resour 12 (1): 1-12.

Wang SM, Li LH, Li Y, Lu XX, Yang QW, Cao YS, Liu X (2011b) Status of plant genetic resources for food and agricultural in China ( () . Journal of Plant Genetic Resources 12(2) : 167-177

Wu ZG, Li XX, Lin X, Jiang W, Tao ZM, Mantri N, Fan CY, Bao XQ (2014) Genetic diversity analysis of yams (Dioscorea spp.) cultivated in China using ISSR and SRAP markers. Genet Resour Crop Ev 61(3): 639650 .

Wenqiang W, Chong C, Qing Z, Jatoi ZA, Yun X, Xiaolong H, Jun X, Wei X, Dongyi H (2019) A comparative assessment of diversity of greater yam (Dioscorea alata) in China. Sci Hortic-Amsterdam, 243: 116-124.

Xu Y, Wu WQ, Xie J, Huang, DY (2014). Genetic diversity of 111 Dioscorea alata linn. germplasms using AFLP markers. J Plant Genet Resour 15(02): 299-304.

Yeh Francis C, Yang RC, Boyle Timothy BJ, Ye ZH, Mao Judy X (1999) POPGENE, version 1.32: the user friendly shareware for population genetic analysis. Molecular Biology and Biotechnology Centre, University of Alberta, Edmonton, AB, Canada.

Yin JM, Zhang PT, Han XY, Wang L, Guo WQ, Li CH, Shi XM, Zhou ZL, Tang ZH, Chen XG, Fan JD (2017) A new bulk purple yam cultivar -'Suyu No.1'. China Vegetables 02: 76-78.

Zannou A, Agbicodo E, Zoundjihékpon J, Struik PC, Ahanchédé A, Kossou DK, Sanni A (2009) Genetic variability in yam cultivars from Guinea-Sudan of Benin assessed by random amplified polymorphic DNA. Afr J Biotechnol 8: 26-36.

\section{Tables}


Table 1 Qualitative and quantitative characters for phenotypic assessment of purple yam accessions

Serial Characters acronym phenotypic classes

no.

Qualitative character

$\begin{array}{lll}1 & \text { Leaf shape (LS) } & 1=\text { Sagittate; } 2=\text { Ovate } \\ 2 & \text { Leaf color (LC) } & 1=\text { Yellowish green; } 2=\text { Dark green } \\ 3 & \text { Petiole color (PC) } & 1=\text { All green with purple base } \\ 4 & \text { Leaf margin color (LMC) } & 1=\text { Green; } 2=\text { Purple } \\ 5 & \text { Leaf vein color (LVC) } & 1=\text { Yellowish green; } 2=\text { Green; } 3=\text { Purple } \\ 6 & \text { Leaf texture (LT) } & 1=\text { Leathery; } 2=\text { Papery } \\ 7 & \text { Stem wing color (SWC) } & 1=\text { Purple red } \\ 8 & \begin{array}{l}\text { Roots on the tuber } \\ \text { surface (RTS) }\end{array} & 1=\text { Few; } 2=\text { Many }\end{array}$

$9 \quad \begin{aligned} & \text { Place of roots on the } \quad 1=\text { Upper; } 2 \text { = Entire tuber } \\ & \text { tuber (PRT) }\end{aligned}$

10 Tuber flesh texture (TFT) $1=$ Smooth; 2 = Grainy

11 Tuber skin color (TSC) $1=$ Brown; 2 = Greyish; $3=$ Purple

12 Tuber flesh color (TFC) 1 =Purple red; 2 =Purple ; 3 =Outer purple red; 4 =Purple with white; 5 =Outer purple

Quantitative character

13 Leaf length (LL) Average leaf length of ten mature leaves $(\mathrm{cm})$.

14 Leaf width (LW) Average leaf width of ten mature leaves $(\mathrm{cm})$.

15 Petiole length $(\mathrm{PL}) \quad$ Average petiole length of ten mature leaves $(\mathrm{cm})$.

16 Concave depth of leaf Average Concave depth of leaf base of ten mature leaves base (CDLB) (cm).

17 Distance between lobes (DBL)

Average the distance of ten mature leaves $(\mathrm{cm})$.

Qualitative and quantitative characters were referred to Wang and Shen (2014).

Table 2 The Shannon diversity index ( () of 12 qualitative traits in four group of purple yam. 
Diversity index (I)

\begin{tabular}{llllll}
\hline Traits & Group I & Group II & Group III & Group IV & Total \\
\hline Leaf shape & 0 & 0 & 0.954 & 0.989 & 1.000 \\
\hline Leaf color & 0 & 0 & 1.000 & 0.989 & 0.996 \\
\hline Petiole color & 0 & 0 & 0 & 0 & 0 \\
\hline Leaf margin color & 0 & 0 & 1.000 & 0 & 0.706 \\
\hline Leaf vein color & 0 & 0 & 1.299 & 1.366 & 1.466 \\
\hline Leaf texture & 0 & 0 & 0 & 0.811 & 0.619 \\
\hline Stem wing color & 0 & 0 & 0 & 0 & 0 \\
\hline Roots on the tuber surface & 0 & 0 & 0 & 0.337 & 0.391 \\
\hline Place of roots on the tuber & 0 & 0 & 0.954 & 0.544 & 0.706 \\
\hline Tuber flesh texture & 0 & 0 & 0 & 0 & 0.811 \\
\hline Tuber skin color & 0 & 0 & 0.811 & 1.272 & 1.272 \\
\hline Tuber flesh color & 0 & 0 & 2.250 & 1.248 & 2.038 \\
\hline Mean & 0 & 0 & 0.689 & 0.630 & 0.834
\end{tabular}

Table 3 Statistical analysis of intra- and inter-group quantitative traits of accessions from four groups. 
$\begin{array}{llllllll}\text { Species Trait } \quad \text { Min./cm } & \text { Max./cm } & \text { Max./Min. } & \text { 'x/cm } & \text { SD } & \text { CV/\% } & I\end{array}$

\begin{tabular}{|c|c|c|c|c|c|c|c|c|}
\hline \multirow[t]{5}{*}{ Group I } & $\mathrm{LL}(\mathrm{cm})$ & 21.31 & 21.31 & - & 21.31 & - & - & - \\
\hline & LW (cm) & 12.64 & 12.64 & - & 12.64 & - & - & - \\
\hline & $\mathrm{PL}(\mathrm{cm})$ & 10.80 & 10.80 & - & 10.80 & - & - & - \\
\hline & CDLB $(\mathrm{cm})$ & 4.32 & 4.32 & - & 4.32 & - & - & - \\
\hline & $\mathrm{DBL}(\mathrm{cm})$ & 8.92 & 8.92 & - & 8.92 & - & - & - \\
\hline \multirow[t]{5}{*}{ Group II } & $\mathrm{LL}(\mathrm{cm})$ & 21.21 & 21.21 & - & 21.21 & - & - & - \\
\hline & $\mathrm{LW}(\mathrm{cm})$ & 10.58 & 10.58 & - & 10.58 & - & - & - \\
\hline & $\mathrm{PL}(\mathrm{cm})$ & 12.28 & 12.28 & - & 12.28 & - & - & - \\
\hline & $\operatorname{CDLB}(\mathrm{cm})$ & 4.66 & 4.66 & - & 4.66 & - & - & - \\
\hline & $\mathrm{DBL}(\mathrm{cm})$ & 7.18 & 7.18 & - & 7.18 & - & - & - \\
\hline \multirow[t]{5}{*}{ Group III } & $\mathrm{LL}(\mathrm{cm})$ & 18.08 & 22.57 & 1.25 & 19.56 & 1.50 & 7.69 & 1.781 \\
\hline & $\mathrm{LW}(\mathrm{cm})$ & 8.92 & 13.20 & 1.48 & 11.42 & 1.54 & 13.44 & 1.906 \\
\hline & $\mathrm{PL}(\mathrm{cm})$ & 8.22 & 10.98 & 1.34 & 9.64 & 0.99 & 10.30 & 2.156 \\
\hline & CDLB $(\mathrm{cm})$ & 1.31 & 4.01 & 3.06 & 2.93 & 0.84 & 28.67 & 2.156 \\
\hline & $\mathrm{DBL}(\mathrm{cm})$ & 7.99 & 10.46 & 1.31 & 8.67 & 0.85 & 9.79 & 1.750 \\
\hline \multirow[t]{5}{*}{ Group IV } & $\mathrm{LL}(\mathrm{cm})$ & 8.54 & 19.66 & 2.30 & 14.75 & 2.42 & 16.39 & 1.949 \\
\hline & LW (cm) & 4.74 & 11.36 & 2.40 & 8.20 & 1.45 & 17.67 & 1.589 \\
\hline & $\mathrm{PL}(\mathrm{cm})$ & 4.53 & 10.23 & 2.26 & 7.64 & 1.41 & 18.48 & 2.061 \\
\hline & $\operatorname{CDLB}(\mathrm{cm})$ & 1.39 & 4.30 & 3.09 & 2.60 & 0.66 & 25.32 & 1.811 \\
\hline & $\mathrm{DBL}(\mathrm{cm})$ & 3.46 & 9.33 & 2.70 & 6.27 & 1.46 & 23.20 & 1.949 \\
\hline \multirow[t]{5}{*}{ Total } & $\mathrm{LL}(\mathrm{cm})$ & 7.18 & 25.8 & 3.59 & 16.73 & 3.30 & 19.73 & 2.051 \\
\hline & LW (cm) & 3.75 & 15.38 & 4.10 & 9.45 & 2.15 & 22.75 & 2.009 \\
\hline & $\mathrm{PL}(\mathrm{cm})$ & 3.77 & 15.31 & 4.06 & 8.56 & 1.77 & 20.68 & 2.073 \\
\hline & CDLB $(\mathrm{cm})$ & 0.83 & 6.02 & 7.25 & 2.85 & 0.85 & 29.82 & 2.032 \\
\hline & $\mathrm{DBL}(\mathrm{cm})$ & 2.11 & 11.89 & 5.64 & 7.15 & 1.68 & 23.50 & 2.120 \\
\hline
\end{tabular}

Min, minimum; Max, maximum, 'x, mean; SD, standard deviation; CV, coefficient of variation; I: Shannonwiener index.

Table 4 List of amplification results of SSR primers. 


\begin{tabular}{lllll} 
Marker & $\mathrm{Na}$ & $\mathrm{Ne}$ & $\mathrm{H}$ & \multicolumn{1}{l}{} \\
\hline YM02 & 3 & 1.946 & 0.486 & 0.824 \\
\hline YM03 & 3 & 1.374 & 0.272 & 0.536 \\
\hline YM07 & 3 & 2.510 & 0.602 & 0.998 \\
\hline YM11 & 3 & 1.649 & 0.394 & 0.717 \\
\hline YM15 & 3 & 2.123 & 0.529 & 0.908 \\
\hline YM16 & 4 & 2.510 & 0.602 & 1.050 \\
\hline YM18 & 4 & 1.667 & 0.400 & 0.794 \\
\hline YM19 & 4 & 2.889 & 0.654 & 1.178 \\
\hline YM20 & 5 & 3.655 & 0.726 & 1.409 \\
\hline Mean & 4 & 2.258 & 0.518 & 0.935 \\
\hline Total & 32 & 20.322 & 4.664 & 8.413
\end{tabular}

$N_{a}$ : observed number of alleles, $N_{e}$ : effective number of alleles, $H$. Nei's gene diversity, l: Shannon's diversity index.

Figures 


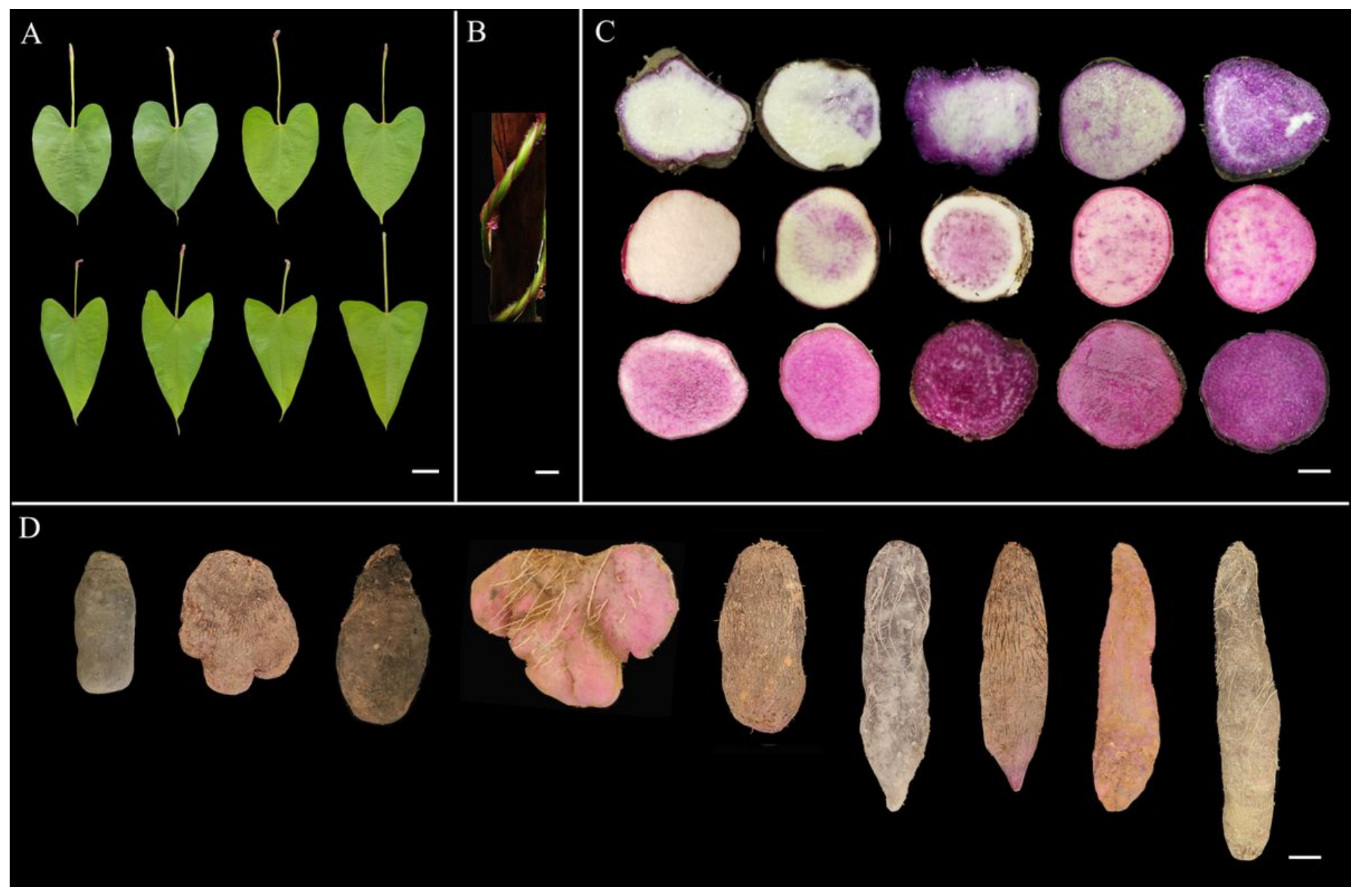

\section{Figure 1}

Phenotypic characteristics of purple yam. The morphology of leaf shape with sagittate and ovate (A), stem wing color are red purple (B), different types of flesh color (C) and tuber skin color (D) were analyzed respectively. Bars of (A), (B), (C) and (D) are $4 \mathrm{~cm}, 1 \mathrm{~cm}, 4 \mathrm{~cm}$ and $4 \mathrm{~cm}$ respectively. 
A

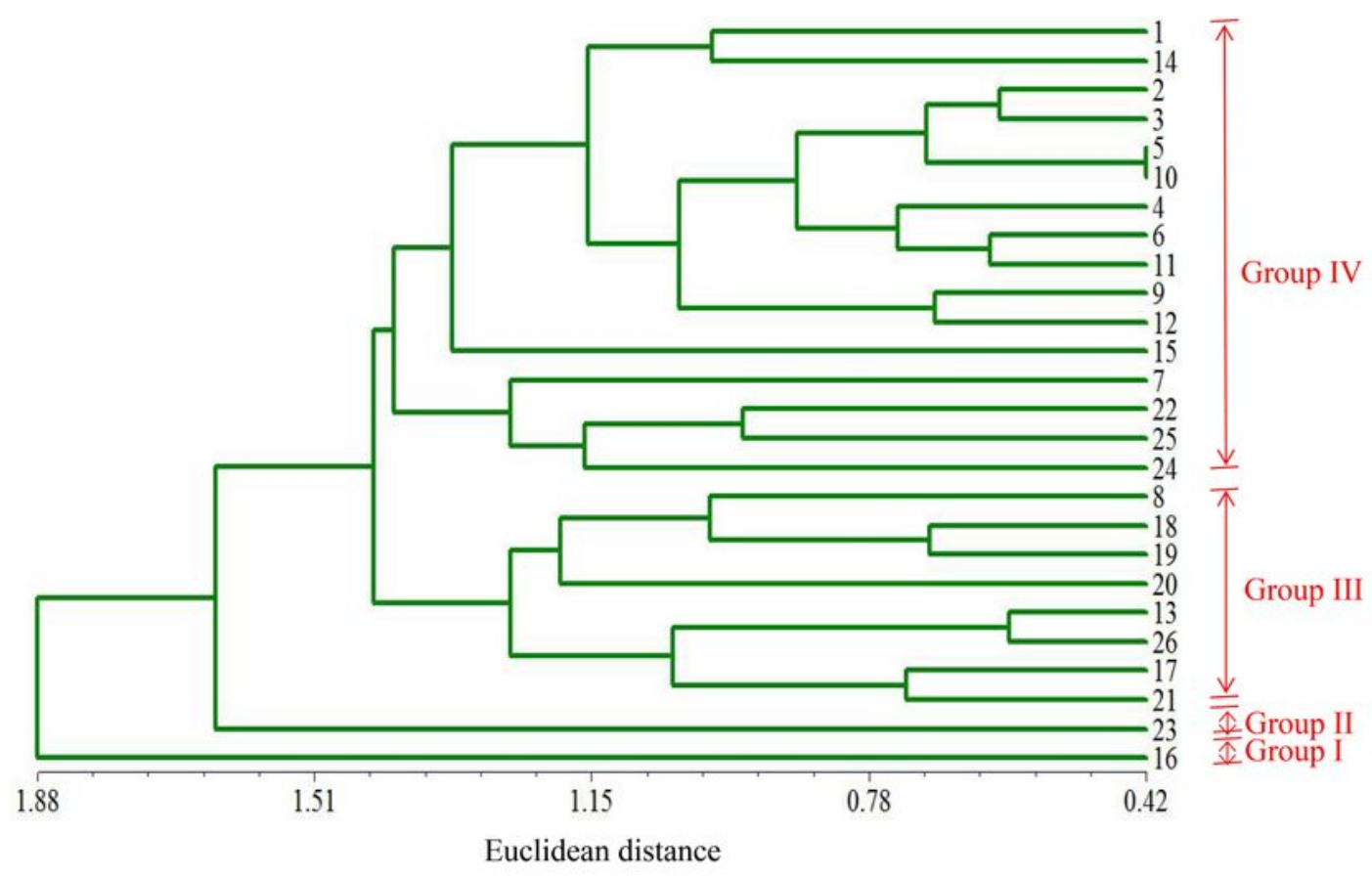

B

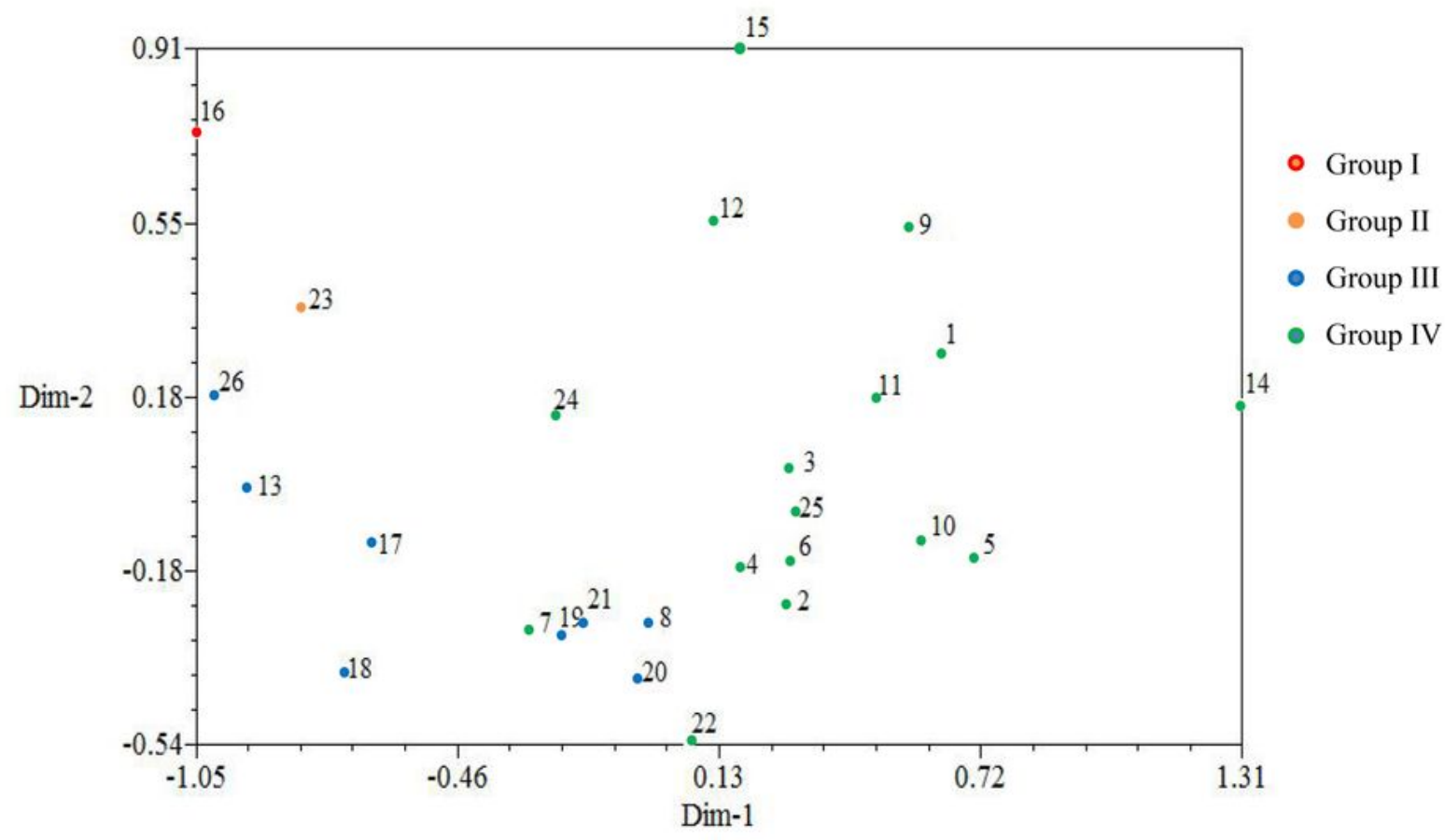

Figure 2

Clustering analysis (A) and Two-dimensional graph of clustering analysis (B) based on morphological data. Dim, dimensional. 
A

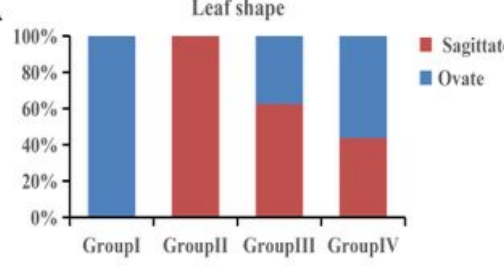

D

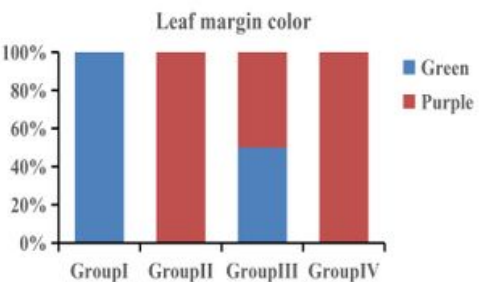

G

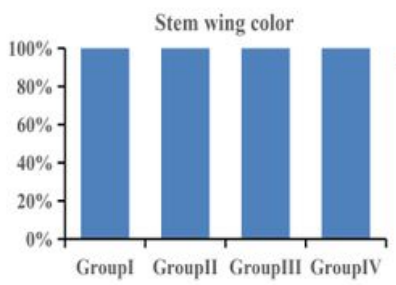

J

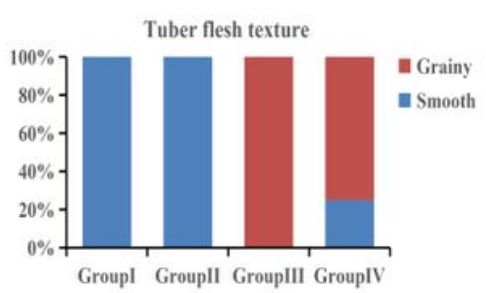

B
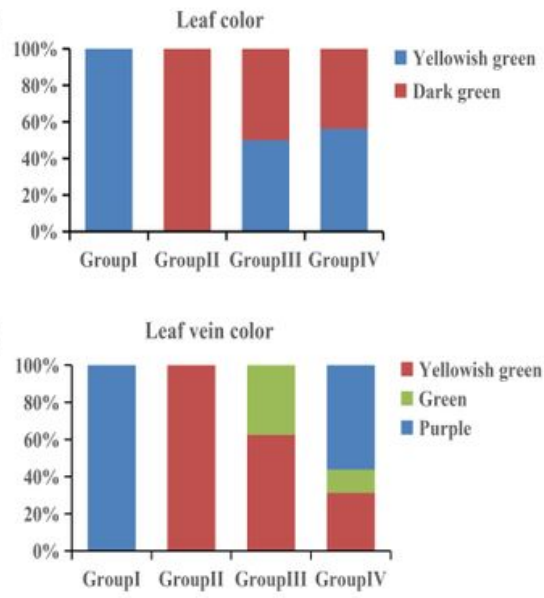

H

- Purple red

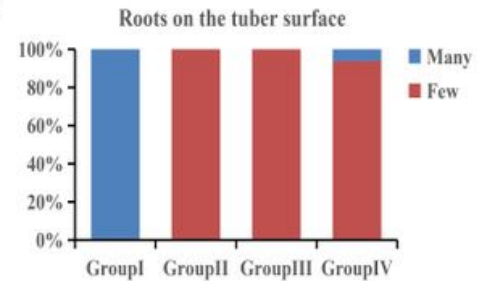

K

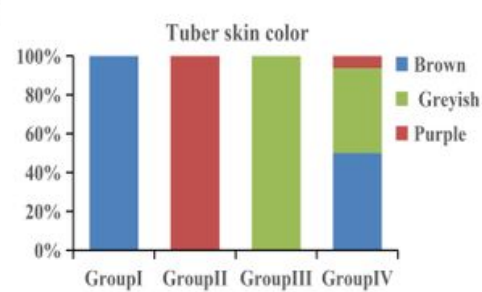

C

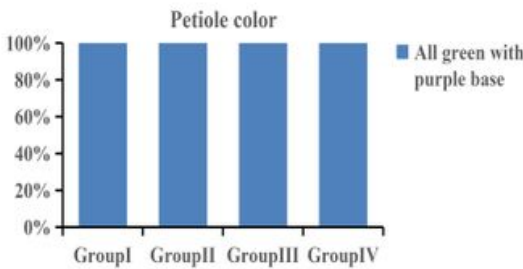

F
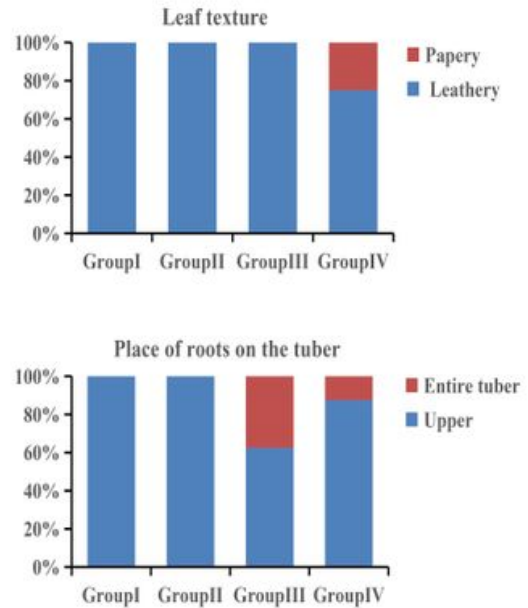

L

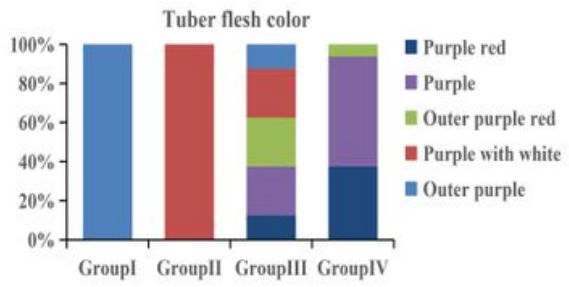

Figure 3

The distribution frequency (\%) of each qualitative trait in four group purple yam accessions. The sample sizes of four groups are $1,1,8$, and 16, respectively. 


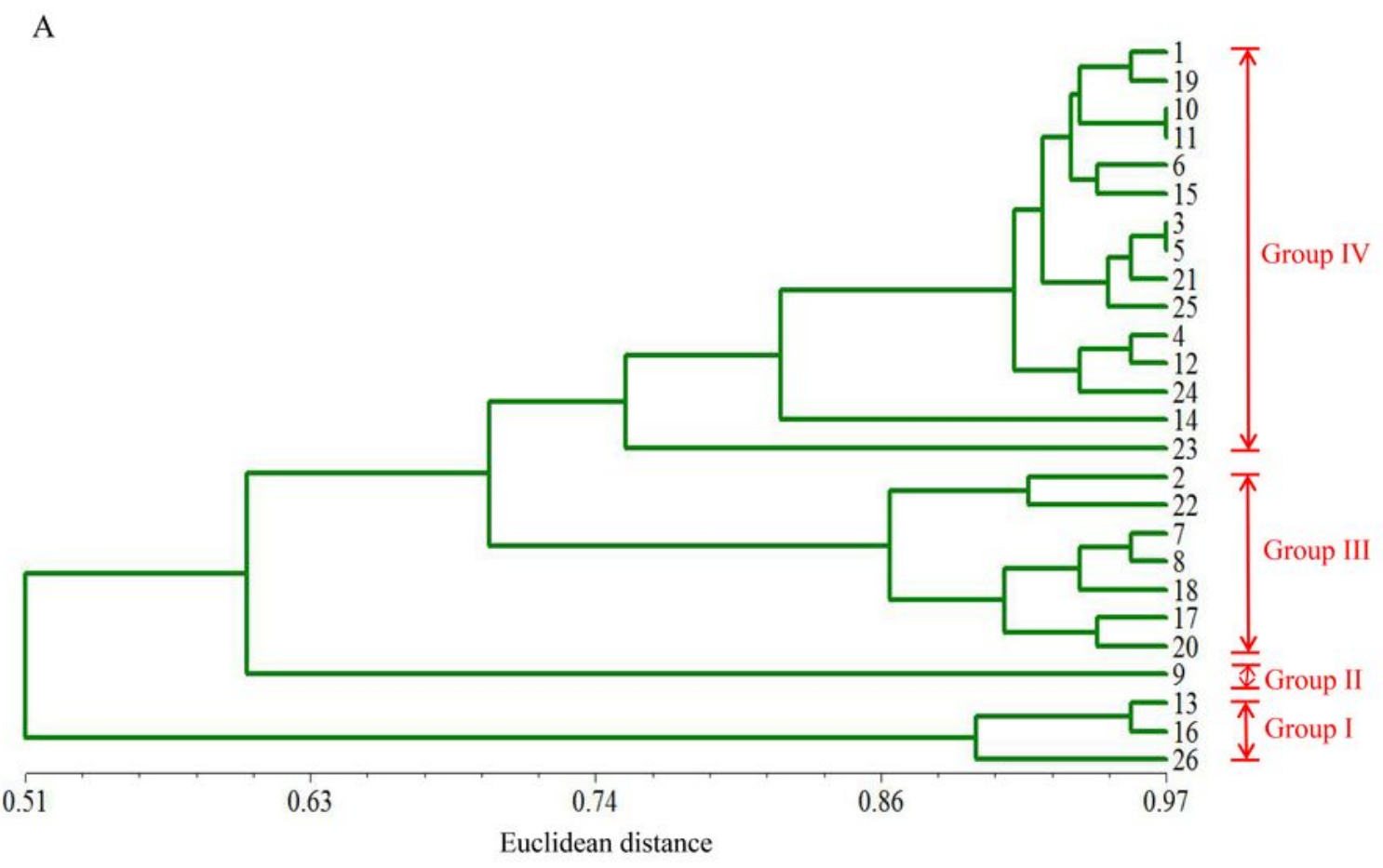

B

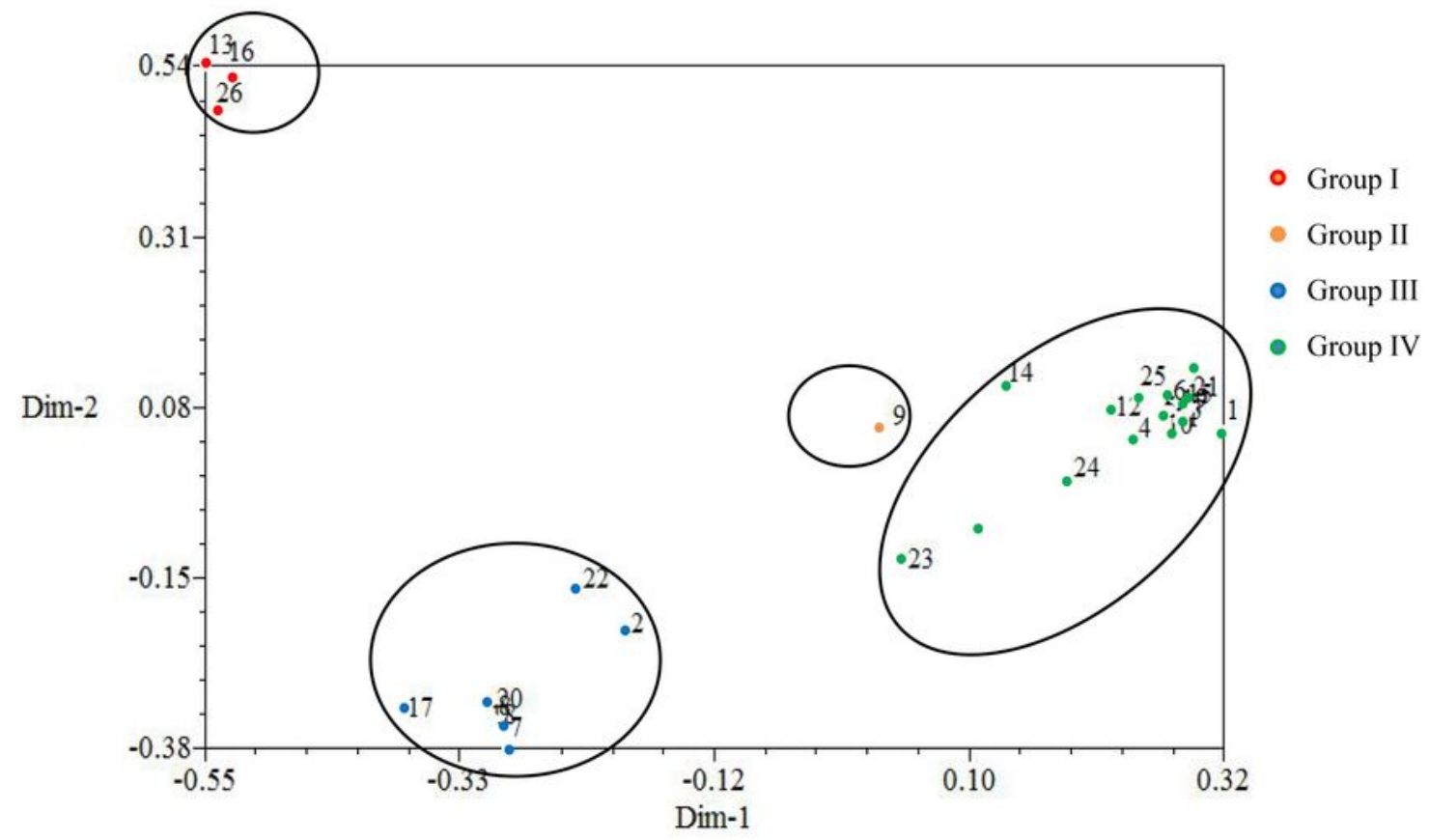

\section{Figure 4}

Clustering analysis (A) and Two-dimensional graph of clustering analysis (B) based on SSR molecular marker data. Dim, dimensional 
A

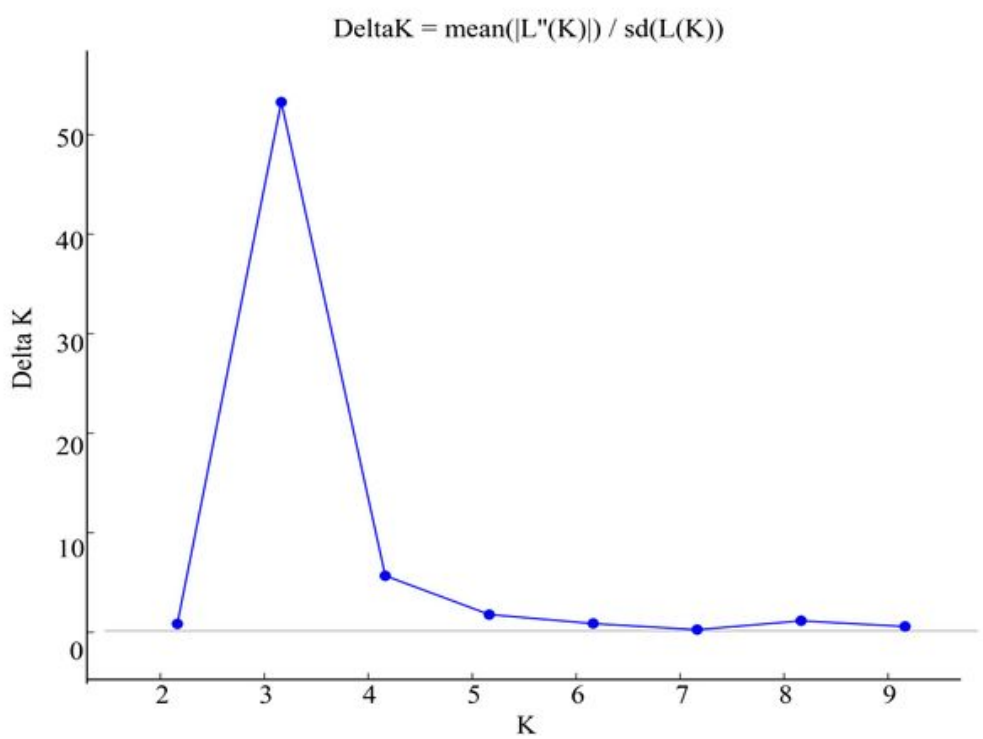

B
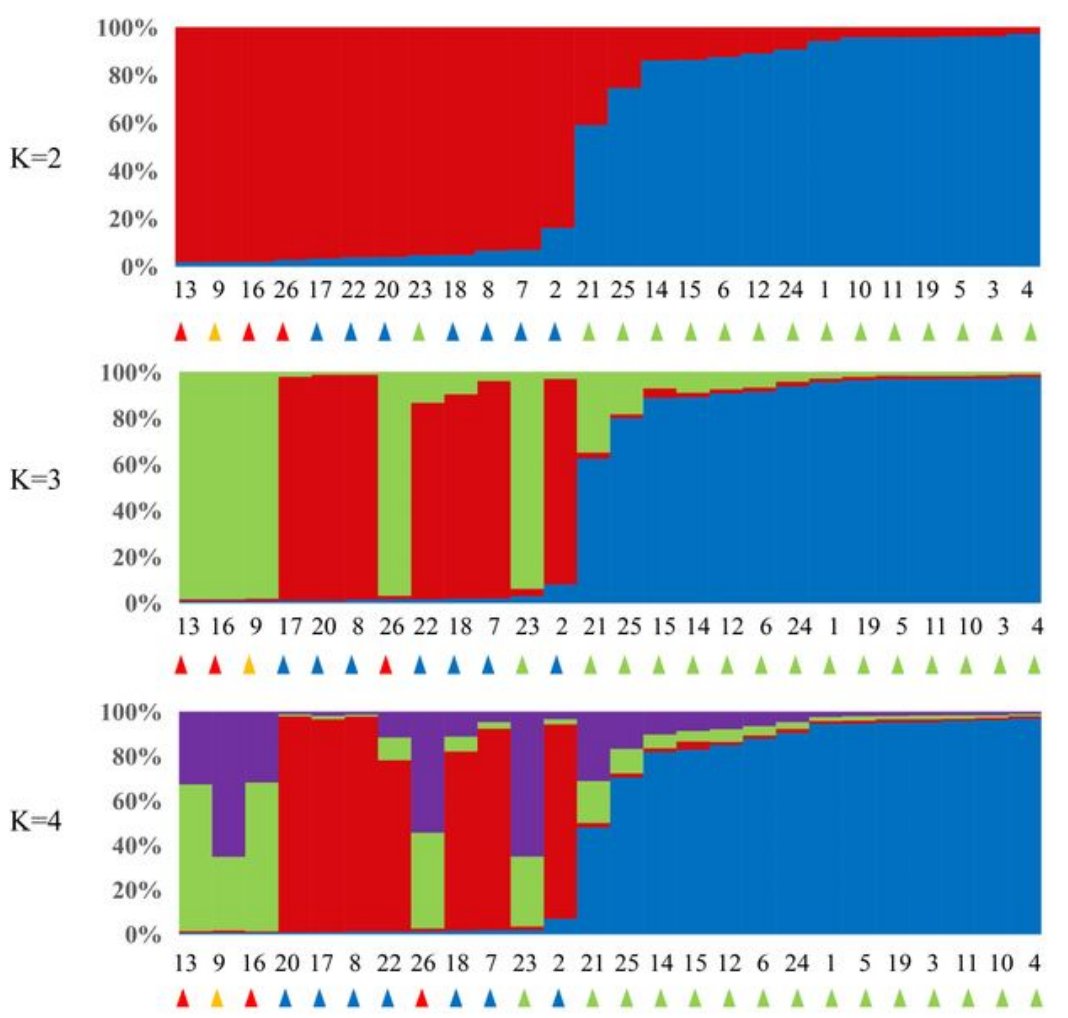

Group I

- Group II

A Group III

A Group IV

\section{Figure 5}

Structure of the genetic diversity of 26 purple yam accessions. (A), $\Delta K$ values for different numbers of populations assumed $(K)$; $(B)$, Population genetic structure at $K=2,3,4$. The groups were based on the polymorphic data of SSR markers

\section{Supplementary Files}


This is a list of supplementary files associated with this preprint. Click to download.

- TableS1.docx

- Tables2.docx

- TableS3.docx

- Tables4.docx

- TableS5.docx

- Tables6.docx 